\title{
Experience of Menopause and Menopausal Transition among Middle aged Women Attending A Periurban Hospital
}

\author{
SARIA TASNIM ${ }^{1}$, MD. ABIDUL HAQUE${ }^{2}$, SUMMYIANAZMEEN ${ }^{3}$
}

\begin{abstract}
:
Objective (s): The objective was to explore frequency of menopause related symptoms among middle aged women and their perception about menopause,

Materials and Methods: This was a cross sectional study carried during March to May 2013 among women aged 45-60 years at the out patient Department of Obstetrics and Gynaecology of a tertiary hospital using structured questionnaire. Information was sought regarding menstrual pattern, self reported menopausal symptoms and attitude towards menopausal transition. Data analysis was done using SPSS version 16.

Results: Total 106 women were interviewed, The mean age of the respondents was $50.3 \pm 53$ years, and $58.5 \%$ were post menopausal and $41.5 \%$ in menopausal transition. More than half $(59.4 \%)$ were illiterate, $32 \%$ were working. Common menopausal symptoms were insomnia $51.8 \%$, body ache $44.3 \%$ and feeling sad $31.3 \%$. Hot flush and night sweats were reported by $50 \%$ and $33 \%$ respectively. Half of them regard menopause as normal and health seeking for menopausal problems was $42.5 \%$.

Conclusion: A significant proportion of women were suffering from vasomotor and psychosomatic symptoms but most of them did not seek treatment. To ensure quality of life health needs of middle aged women should be identified and their views towards menopause incorporated in formulating services for them
\end{abstract}

Key words: Menopause, menopausal symptoms, perception, middle age

\section{Introduction:}

Menopause is an important life event in women's life resulting from loss of ovarian follicles and marked by permanent cessation of menstruation ${ }^{1}$. The change does not occur abruptly but may take 1-9 years producing symptoms in a middle aged woman due to gradual decline of ovarian function and this time period is called menopausal transition².

The meaning of menopause is different among medical researchers and modernist feminist researchers ${ }^{3}$. The medical opinion conceived menopause as an estrogen deficiency state and associated with a variety of acute and chronic conditions, both physical and psychological, ranging from hot flushes to more severe cardiovascular and bone diseases ${ }^{4}$. The World Health Organization has indexed menopause in the international classification of diseases ${ }^{2}$. Within feminist discourse the disease model of menopause is challenged and menopause is reconstructed as a "normal life change" transition, a positive, significant 'rite of passage' that provides space for re-evaluation and new-found freedom ${ }^{5}$.

Symptoms related to menopause varies in different parts of world. All women do not experience similar symptom ${ }^{6}$. Population based studies reported higher prevalence $(40-70 \%)$ of menopausal symptoms among Caucasians and lower prevalence (10-50\%) in Asian countries $^{7}$. Study from Singapore reported among women aged $45-60$ years $72 \%$ were not bothered by any symptoms of menopause. Evidence shows that somatic and psychological symptoms are less frequent among Asian women as compared to western

1. Professor \& Head of Obstetrics \& Gynaecology, Centre for women and Child Health, Ashulia

2. Professor of Epidemiology, Institute of Child and Mother Health

3. Junior consultant, Gynae, Centre for women and Child Health 
counterpart ${ }^{9}$. Study from India reported working women suffer more from psychological problems whereas non working women showed a greater incidence of somatic symptoms ${ }^{10}$.

Menopause is welcomed as a favorable event among rural women of India which is attributed to freedom from cultural restrictions imposed on younger women and the burden of childbirth as well as the discomforts associated with menstruation ${ }^{11}$. To the Muslims it heralds a time for enhancing religious activities and pilgrimage ${ }^{12}$. As the sociocultural factors can alter women's response expression are less common in society where menopause is viewed as positive rather than negative event ${ }^{13}$.

Women's health is a global concern now a day. With increase life expectancy a woman spend more than a third of her life post menopausal. Menopausal symptoms may affect health related quality of life ${ }^{14}$. Information about menopausal experiences among women is important for healthcare personnel to provide appropriate and specific interventions ${ }^{15}$. Studies on issues relating to menopause are lacking in Bangladesh. The current study was aimed to explore prevalence of menopause related symptoms and perception towards menopause among a group of middle aged women

\section{Method:}

This was a cross sectional study. A total 106 women aged 45 years and above who attended Gynae out patient department of Institute of Child and Mother Health (ICMH) either as a patient or attendant during 15th march-15th may 2013 was interviewed using a structured questionnaire. Ethical clearance was obtained from institutional review board and written informed consent was obtained from respondents. Menopausal symptoms reported were taken for a recall period of last three months from the date of interview. The symptoms reported were divided into three categories, vasomotor, psycho somatic, and genitourinary complains. Data were analyzed using SPSS version 16 and presented as mean and frequencies.

\section{Results:}

Mean age was $50.3 \pm 5.3$ years and about $46 \%$ of women between 45 to 50 years attained menopause (Table 1). Forty percent (40\%) were literate, $16 \%$ were widow and $24.5 \%$ had secondary education (Table-2). About $30.2 \%$ were employed (Figure 1). There were multiple responses to different symptoms. Among vasomotor symptoms hot flush $50 \%$, burning extremity $48.1 \%$, and night sweat $33 \%$. (Figure 2). Commonly psychosomatic symptoms were anxiety $54.7 \%$, insomnia $51.89 \%, 31.3 \%$ felt sad and $16.03 \%$ felt annoyed. Body ache was a common complain $44.3 \%$ (Figure 3). Urinary complains were quite common and $9.43 \%$ noticed dryness of vagina (Figure 4). Half of the women regard menopause as a natural process and few of them are concerned about body aches and loss of feminity (Table 3). Although more than half of women did not notice any problem with sex but high proportion are not sexually active beyond 51 years (Table 4 ).

Table-I

Distribution according to age and menopause status

\begin{tabular}{lccc}
\hline Age of women & $\begin{array}{c}\text { Irregular } \\
\text { Menstruation }\end{array}$ & $\begin{array}{c}\text { Post } \\
\text { menopause }\end{array}$ & Total \\
\hline $45-50$ & 43 & 37 & 80 \\
$51-55$ & 1 & 7 & 8 \\
$\geq 56$ & 18 & 18 \\
\hline \multicolumn{4}{c}{ Table-II } \\
\multicolumn{4}{c}{ Distribution according to Sociodemographic } \\
\multicolumn{3}{c}{ Characteristics } \\
Characteristics & Frequency \\
\hline Education & Percent \\
Primary & 17 & 16.0 \\
Secondary and above & 26 & 24.5 \\
Illiterate & 63 & 59.4 \\
Marital status & \multicolumn{3}{c}{} \\
Stay with husband & 88 & 83.0 \\
Widow & 17 & 16 \\
Unmarried & 1 & .9 \\
\hline
\end{tabular}

Distribution according to occupation

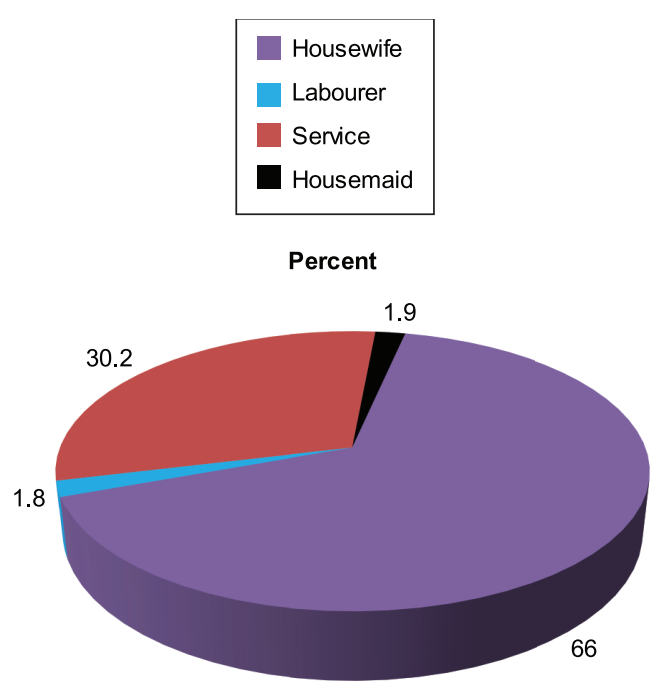

Fig.-1: Occupation of participants 


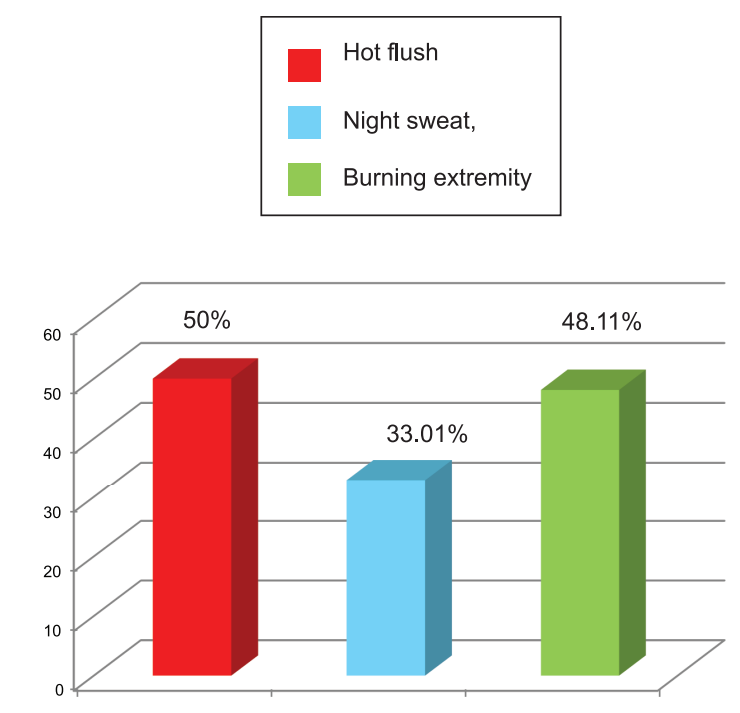

Fig.-2: Vasomotor symptoms

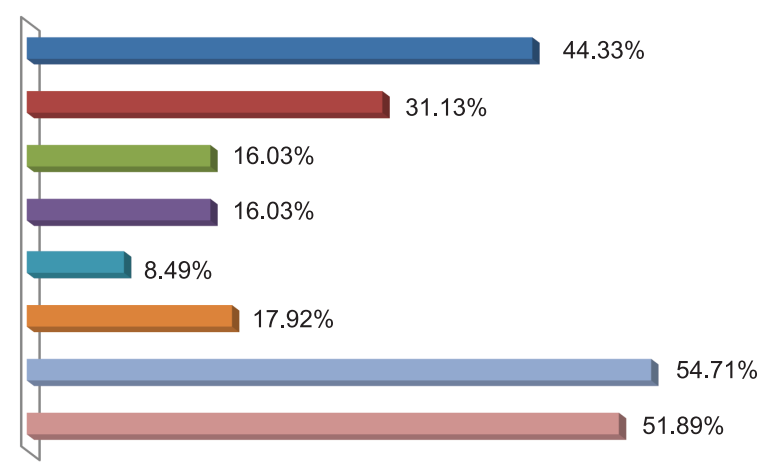

Fig-3: Psychosomatic problems

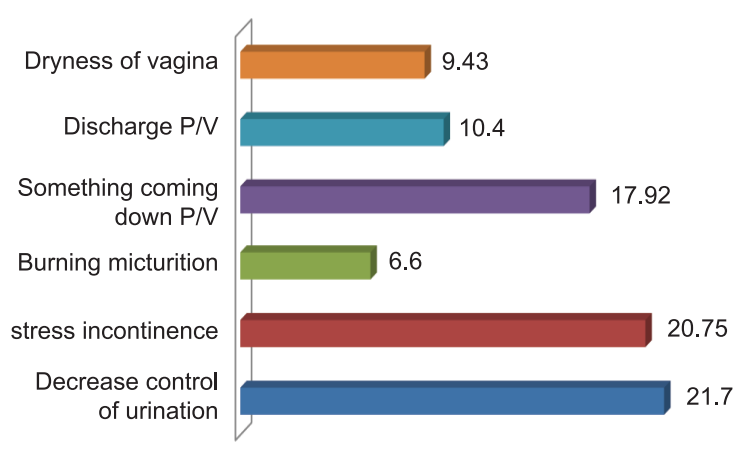

Fig.-4: Genitourinary problems

Table-III

Distribution according to Attitude towards menopause

\begin{tabular}{lcc}
\hline $\begin{array}{l}\text { Attitude towards } \\
\text { menopause }\end{array}$ & Frequency & Percentage \\
\hline $\begin{array}{l}\text { Happy about menstruation } \\
\text { cessation }\end{array}$ & 15 & 14.1 \\
Considers as Natural Process & 53 & 50.0 \\
Fear Loss of Feminity & 4 & 3.7 \\
Considers as Ageing process & 3 & 2.8 \\
Prone to body aches & 19 & 17.9 \\
$\begin{array}{l}\text { Others } \\
\text { Took treatment for problem }\end{array}$ & 7 & 6.6 \\
related with menopause & 45 & 42.5 \\
\hline
\end{tabular}

Table-IV

Distribution according to current sexual practice with age

\begin{tabular}{|c|c|c|c|c|c|c|}
\hline \multirow[t]{2}{*}{ Current sexual practice } & \multicolumn{2}{|c|}{$45-50(n=77)$} & \multicolumn{2}{|c|}{$\geq 51(n=21$} & \multicolumn{2}{|c|}{ Total $(\mathrm{n}=98)$} \\
\hline & $\mathrm{N}$ & $\%$ & $\mathrm{~N}$ & $\%$ & $\mathrm{~N}$ & $\%$ \\
\hline Not sexually active & 17 & 17.35 & 10 & 47.62 & 27 & 27.55 \\
\hline Decrease sex urge & 27 & 35.06 & 3 & 14.28 & 30 & 30.61 \\
\hline Dysparunia & 7 & 9.09 & 0 & 00 & 7 & 7.14 \\
\hline Does not enjoy sex & 9 & 11.6 & 3 & 9.5 & 11 & 11.2 \\
\hline Husband sick & 6 & 7.9 & 4 & 19.04 & 10 & 10.20 \\
\hline No problem with intercourse & 45 & 58.44 & 5 & 23.80 & 50 & 51.02 \\
\hline
\end{tabular}

\section{Discussion}

Menopause not only mark the end of reproductive function but also introduce her to anew phase of life ${ }^{16}$. Classical symptoms of menopause may interfere with physical and mental well being and quality of life ${ }^{9}$. More frequent symptom in the current study was sleep disturbance, anxiety and hot flush, a study from Malaysia reported joint and muscular discomfort $80.1 \%$, physical and mental exhaustion $67.1 \%$, sleeping problems $52.2 \%$, hot flushes and sweating $41.6 \%$ and irritability $37.9 \%{ }^{17}$. In a study from Nepal most frequently reported symptoms were, sleeping 
problems $78.7 \%$, physical and mental exhaustion $73.5 \%$, hot flushes $69.7 \%$, joint and muscular discomfort $68.6 \%$ and dryness of vagina $61.6 \%{ }^{14}$. Hot flushes and sweating were the most common complaints among Turkish women ${ }^{18}$

Study among a population of 40-60 years old rural Bangladeshi women common problem was weakness, vertigo, aches and pain all over body. Sleep disturbance and hot flush was reported $29.4 \%$ and $14.7 \%$ respectively ${ }^{19}$. Rahman et al reported most prevalent symptoms include feeling tired $92.90 \%$, headache $88.80 \%$, joint and muscular discomfort $76.20 \%$, physical and mental exhaustion $60.90 \%$ and sleeplessness $54.40 \%{ }^{20}$. In Thailand most common symptoms were dizziness and tiredness and $26 \%$ reported hot flush ${ }^{21}$. Study from Pakistan showed bodyachae $81.7 \%$, hot flushes $66.3 \%$ and lack of energy in $68.8 \% 13$.

Globally the perception towards menopause varies widely. Some observes a positive view and the rest has either negative or neutral attitude. In western society the time of menopause is characterized by loss of youth, beauty, fertility, libido, feminity and calcium, so medicalization of menopause is common ${ }^{1}$. On the other hand Asian women view menopause as freedom from pregnancy. Study from Iraq reported $71.2 \%$ women perceive menopause in a negative way ${ }^{22}$. Attitude towards menopause may also be influenced by increased level of physical and mental stress requiring support and coping mechanism in this age group 22

Turkish women expressed conflicting views where menopause transition was viewed negatively as the end of youth by some while others viewed positively as freedom from feminine hygienic products, contraception, pregnancy and the end of uncleanness $^{18}$. In youth oriented society women may feel negatively about changes in appearance and feminity ${ }^{23}$. In the current study half of them considers menopause as a natural process but most of them are suffering from different menopausal symptoms mainly psychosocial problems. About $20 \%$ are concerned about vulnerability to body aches. They are not aware why the symptoms are occurring nor they know how they can help themselves to overcome the problems.

It is a common phenomenon that Asian women heralds menopause with a tranquil acceptance ${ }^{8}$. Studies reported menopause accepted as natural process by $78.7 \%^{13}, 85.8 \%^{22}$, and $82.58 \%^{24}$ respectively. However, lack of knowledge and awareness about the menopausal symptoms and its consequence is common ${ }^{25,13,20}$. In the current study some of the menopausal symptoms were severe enough to affect their normal life style while $54.7 \%$ did not seek any treatment and some seek treatment due to other associated problems. None mentioned about hormone replacement therapy (HRT). This may be due to lack of awareness or non-availability of any specialized service for such women and higher cost of the treatment. Seeking treatment for menopausal symptom is often low as is expressed in current study. Among Asian women it is a common belief that such problems are natural process of ageing and are an expected part of life ${ }^{21}$, HRT is not practiced commonly.

Alteration of sexual practice is a common phenomenon in postmenopausal women ${ }^{11}$. Study among Mayan \& Greek with rural women found that they enjoy sex as they did not have the fear to become pregnant again ${ }^{1}$. In the current study decrease libido or sexual desire was quite common problem, $54 \%$ of postmenopausal and $32 \%$ of premenopausal women were not sexually active. However, about half of women said that they do not feel any change. In our society talking about sexual life is a taboo topic and considered very private. It may be possible that women avoided expressing any concern regarding sexual practice, so there is chance of underreporting about the problems or changes in current sexual practice.

Studies among Turkish and Pakistani women reported decrease sexual desire $39.7 \%$ and $32.3 \%$ respectively ${ }^{18.26}$. Apart from the physiological and psychological changes of menopause factors influencing sexuality, health status, dissatisfaction of relationship with partner, economic status and sociocultural context.

\section{Conclusion:}

Menopause is commonly perceived as a natural process. Complains relating to vasomotor and psychological symptoms were common but those were not perceived as problem enough to seek treatment. Although expression of a limited number of women regarding menopause can not be generilzable but this gives an insight to their perspective. Incorporating women's views is important to formulate appropriate and specific intervention to address their special needs. 


\section{References:}

1. Beckmann CRB et al (Eds) 1995: Menopause In obstetrics \& Gynaecology, $2^{\text {nd }}$ ed. Baltimune Williams \& wilkins; 381-389.

2. World Health Organization. Research on the menopause in the 1990s (Report of a WHO scientific group, WHO Technical Report Series, 866). Geneva: World Health Organization 1996.

3. Murtagh, M. and Hepworth, J. Menopause as a long-term risk to health: Implications of general practitioner accounts of prevention for women's choice and decision-making. Sociology of Health and Illness. 2003; 25(2), 185-207.

4. Goldstein, D. When ovaries retire': contrasting women's experiences with feminist and medical models of menopause. Health. 2000; 4(3), 309-23.

5. Coupland, J. and Williams, A. Conflicting discourses, shifting ideologies: pharmaceutical, 'alternative' and feminist emancipatory texts on the menopause. Discourse and Socie; 2002; 13(4) 419-45.

6. Avis N E, Stellato R, Crawford S, Broberger J, Ganz P, Cain V, Kagawa SM. Is there a menopausal syndrome? Menopausal status and symptoms across racial/ethnic groups. Soc Sci Med. 2001; 52(3): 345-6.

7. Avis NE, Crawford SL, McKinlay SM): Psychosocial, behavioral, and health factors related to menopause symptomatology. Womens Health. 1997; 3:103-120.

8. Foo-Hoe Loh, Menopause and the Asian Women. Menopausal Medicine 2007; 15, (1): S 6-10

9. Fuh J L, Wang SJ, Lu SR, Juang KD, Chiu LM The Kinmen women-health investigation (KIWI): a menopausal study of a population aged 40-54. Maturitas. 2001;39:117-124.

10. Kakkara V, Kaurb D., Chopraa K., Kaura A., Kaura I Assessment of the variation in menopausal symptoms with age, education and working/non-working status in north-Indian sub population using menopause rating scale (MRS). Maturitus. 2007; 57, (3): 306-314.

11. Aaron R, Muliyil J, Abraham S . Medico-social dimensions of menopause: a cross-sectional study from rural south India. Natl Med J India 2002; 15(1): 14-7.

12. Damodaran $P$, Subramaniam R, Omar $S Z$, Nadkarni P, Paramsothy M. Profile of a Menopause Clinic in an Urban Population in Malaysia Singapore Med J. 2000;41(9) : 431-435

13. Nisar N, Zehra N, Haider G, Munir A, Naeem A. Knowledge, attitude and experience of menopause. J Ayub Med Coll Abottabad 2008; 20(1): 56-59

14. Neena C, Chandrashekhar T S. Frequency of symptoms, determinants of severe symptoms, validity of and cut-off score for Menopause Rating Scale (MRS) as a screening tool: A crosssectional survey among midlife Nepalese women BMC Women's Health. 2011;30 doi:10.1186/ 1472-6874-11-30

15. Twiss JJ, Wegner J, Hunter M, Kelsay M, RatheHart M, Salado W. Perimenopausal symptoms, quality of life, and health behaviors in users and nonusers of hormone therapy. J Am Acad Nurse Pract, 2007; 19:602-613.

16. Subha Ray Is Menopause a Health Risk for Bengali Women? The Open Anthropology Journal. 2010; 3: 161-167

17. Rahman SA1, Zainudin SR, Mun VL. Assessment of menopausal symptoms using modified Menopause Rating Scale (MRS) among middle age women in Kuching, Sarawak, Malaysia. Asia Pac Fam Med. 2010;22.9(1):5. doi: 10.1186/1447-056X-9-5.

18. Ayranci, U., Orsal, O., Arslan, G., \& Emeksiz, D. F. Menopause status and attitudes in a Turkish midlife female: an epidemiological study. BMC Women's Health. 2010;10:1. doi: 10.1186/ 1472-6874-10-1.

19. Nahar S, Sadiqa T K, Mamunur R, Rukia K, Yasmin R, Humayun K). Menopause in rural Bangladeshi women.2006 Research report. Dhaka

20. Rahman S, Salehin F, lqbal A. Menopausal symptoms assessment among middle age women in Kushtia, Bangladesh. BMC Res Notes. 2011;4:188. 
21. Punyahotra $S$, Sennerstein $L$, Lehert $P$ Menopausal experiences of Thai women. Part 1: Symptoms and their correlates Maturitas 1997; 26:1-7.

22. Mustafa G N, Sabir J M Perceptions and experience regarding menopause among menopausal women attending teaching hospitals in Erbil city, Global journal of Health Science. 2012: 4 (3): 170-178

23. Aarti Kanulagekar. Menopause and Feminity: Qualitative enquiry into menopause of urban women from Pune, Maharastra. Anthropologist. 2010;12 (1): 23-26
24. Tanira S, Wazed F, Sultana A, Amin R, Sultana K, Ahmad S. Knowledge, attitude and experience of Menopause - an urban based study in Bangladesh. J Dhaka Med Coll. 2009; 18(1): 33-36.

25. Nahid Yasmin1, Sayeeda Sultana, Shahin Akhter Jahan Habib, Khodeza Khatun Intervention approach to the menopausal women in rural Bangladesh Bangladesh Medical Journal. 2009;38, No. (1): :-14

26. Ozumba B. C, Obi S. N., Obikili, W P. Age, symptoms and perception of menopause Among Nigerion women. J Obestet Gynecol Ind. 2004; 54(6), 575-8. 